\title{
Antifungal susceptibilities of opportunistic filamentous fungal pathogens from the Asia and Western Pacific Region: data from the SENTRY Antifungal Surveillance Program (2011-2019)
}

\author{
Michael A. Pfaller ${ }^{1,2} \cdot$ Cecilia G. Carvalhaes ${ }^{1} \cdot$ Paul Rhomberg $^{1} \cdot$ Shawn A. Messer $^{1} \cdot$ Mariana Castanheira $^{1}$
}

Received: 22 March 2021 / Revised: 27 May 2021 / Accepted: 31 May 2021 / Published online: 30 June 2021

(c) The Author(s) 2021. This article is published with open access, corrected publication 2021

\begin{abstract}
Antifungal surveillance is an important tool to monitor the prevalence of uncommon fungal species and increasing antifungal resistance throughout the world, but data comparing results across several different Asian countries are scarce. In this study, 372 invasive molds collected in the Asia-Western Pacific region in 2011-2019 were susceptibility tested for mold-active triazoles (isavuconazole, posaconazole, voriconazole, and itraconazole). The collection includes 318 Aspergillus spp. isolates and 53 non-Aspergillus molds. The MIC values using CLSI methods for isavuconazole versus Aspergillus fumigatus ranged from 0.25 to $2 \mathrm{mg} \mathrm{l}^{-1}$. Isavuconazole, itraconazole, posaconazole, and voriconazole acted similarly against $A$. fumigatus. The mold-active triazoles exhibited a wildtype phenotype to most of the Aspergillus spp. isolates tested ( $>94 \%)$, but poor activity against Fusarium solani species complex and Lomentospora prolificans. Voriconazole was most active against the Scedosporium spp. and posaconazole was most active against the Mucorales. In summary, isavuconazole displayed excellent activity against most species of Aspergillus and was comparable to other mold-active triazoles against non-Aspergillus molds.
\end{abstract}

\section{Introduction}

Invasive mold infections (IMI) threaten to limit the lifesaving advances of modern medical technology [1-3]. The genera Aspergillus, Fusarium, Lomentospora, Scedosporium, and molds belonging to the order Mucorales have been termed the "Big Five" mold killers of humans [3]. Whereas much of the literature concerning the species distribution and antifungal resistance profiles of the species causing IMI has focused on isolates from North America and Europe [4-7], the greatest burden of fungal disease in the world resides in the Asia and the Western Pacific (APAC) region $[2,8]$. Numerous factors specifically contribute to the excess fungal diseases in APAC, including a tropical environment in much of the region, inadequately trained healthcare personnel, overuse of steroids and antimicrobials, healthcare practices that are compromised by underfunding, and excessive patient loads in public sector

Mariana Castanheira

mariana-castanheira@jmilabs.com

JMI Laboratories, North Liberty, IA, USA

2 University of Iowa, Iowa City, IA, USA hospitals [8]. Further compromising the diagnosis and treatment of IMI in APAC is the lack of high-quality microbiology laboratories and a limited awareness of fungal disease [8]. Although conventional microscopy and culture are available in most settings, few laboratories perform nucleic acid sequencing or matrix-assisted laser desorption ionization-time of flight mass spectrometry (MALDI-TOF MS) for fungal identification and antifungal susceptibility testing is rarely performed on filamentous fungi [8]. These limitations highlight the need for quality laboratory support, training in medical mycology, and improved access to modern medical technology to facilitate the diagnosis and treatment of IMI in the APAC region [8].

Antifungal resistance is increasingly noted among filamentous fungi throughout the world $[2,4,6,9-12]$. Although acquired resistance to the triazole antifungal agents in isolates of Aspergillus fumigatus has been seen largely in European isolates [5, 7, 13], both acquired and intrinsic resistance among Aspergillus and other less common molds have been reported from the APAC region $[2,8,9,12,14,15]$. Given the unpredictable susceptibility of emerging molds to the available antifungal agents, routine susceptibility testing has been deemed essential for all laboratories associated with tertiary care medical centers $[8,9]$. 
The increasing incidence of IMIs in the APAC regions has spurred both small- and large-scale surveillance efforts in Australia [12, 16, 17], India [18, 19], Japan [20], Korea $[21,22]$, Indonesia [23], Thailand [24, 25], Taiwan [14, 26], and several other countries $[2,12,15]$. One of the limitations of the existing surveillance data from the APAC region is that many of these reports are limited to a single institution and most fail to compare results across cities or countries.

The SENTRY Antifungal Surveillance Program is a survey that has been active globally since 1997, reporting on the frequency of pathogen occurrence and pathogen susceptibility to various antifungal agents [27-29]. The SENTRY Program remains one of the only global antifungal surveys that monitors resistance in Aspergillus species and other molds. Given the high degree of antifungal resistance in many of the emerging molds, understanding the activity, efficacy, and limitations of the available antifungal agents is critical for the management of these potentially life-threatening infections [6, 9-11].

One of the important features of the SENTRY Antifungal Surveillance Program is the provision of reference quality fungal identification and antifungal susceptibility testing results to participating laboratories that may lack mycological expertise. This service is dearly needed for APAC laboratories, where identification and antifungal susceptibility testing of filamentous fungi is often lacking and the variability in both species identification and antifungal susceptibility is considerable [2, 8, 9, 12].

In the present study, we summarized the results of the APAC component of the SENTRY Program between 2011 and 2019, comparing the activities of four mold-active triazoles tested against a collection of 372 invasive molds, including Aspergillus spp (318 isolates), Mucorales (13 isolates), Scedosporium spp (17 isolates), and 12 different species of other rare molds (23 isolates). All isolates were tested using the reference broth microdilution (BMD) method as recommended by the Clinical and Laboratory Standards Institute (CLSI). Emerging resistance was evaluated by species-specific epidemiological cutoff values (ECVs), where available.

\section{Materials and methods}

\section{Organisms}

A total of 372 non-duplicate clinical isolates of molds were collected in 17 hospitals located in six Asia-Pacific countries during a 9-year period (2011-2019). Isolates were recovered from patients with bloodstream infections (9 isolates), pneumonia in hospitalized patients (262 isolates), skin and skin structure infections (24 isolates), and from other non-specified sites of infection (77 isolates).

\section{Identification methods}

Mold isolates were submitted to JMI Laboratories (North Liberty, Iowa, USA), where identification was confirmed by morphological, biochemical, MALDI-TOF MS as well as molecular methods when necessary $[11,30]$. Mold isolates were subcultured to assess purity and viability, then inoculated into Sabouraud Liquid Broth Modified (Becton, Dickenson and Company, Sparks, Maryland, USA). Total protein extraction was performed using formic acid and then submitted to MALDI-TOF MS using the MALDI Biotyper (Bruker Daltonics, Billerica, Massachusetts, USA). Isolates not scoring $\geq 2.0$ by spectrometry were submitted to $28 \mathrm{~S}$ ribosomal subunit sequencing, followed by analysis of $\beta$ tubulin (Aspergillus spp.), translation elongation factor (TEF; Fusarium spp.), or internal transcribed spacer regions (all other species of filamentous fungi), [11, 15, 30, 31]. Nucleotide sequences were analyzed using Lasergene software (DNASTAR, Madison, Wisconsin, USA) and compared to sequences using BLAST (https://blast.ncbi. nlm.nih.gov/Blast.cqi). TEF sequences were analyzed using the Fusarium multilocus sequence typing (MLST) database (http://www.westerdijkinstitute.nl/fusarium/).

\section{Susceptibility testing}

All mold isolates were tested by BMD as described by the CLSI M38 document [32]. Frozen-form microdilution panels using RPMI 1640 broth supplemented with MOPS (3-[N-Morpholino]propane sulfonic acid) and $0.2 \%$ glucose were inoculated with $0.4-5.0 \times 10^{4} \mathrm{CFU} \mathrm{ml} \mathrm{m}^{-1}$ conidial suspensions for a final concentration of $0.2-2.5 \times 10^{4} \mathrm{CFU}$ $\mathrm{ml}^{-1}$. Minimal inhibitory concentration (MIC) endpoints were read at the lowest concentration that produced visually clear wells after $24 \mathrm{~h}$ (Mucorales group), $48 \mathrm{~h}$ (Aspergillus spp., other molds), and $72 \mathrm{~h}$ (Scedosporium spp.). Isavuconazole was included in the SENTRY Program in 2017.

CLSI clinical breakpoints have only been established for voriconazole against Aspergillus fumigatus; however, ECVs have been developed by CLSI for isavuconazole, itraconazole, posaconazole, and voriconazole against Aspergillus flavus species complex (SC), Aspergillus terreus SC, and Aspergillus niger SC, and for isavuconazole and itraconazole against A. fumigatus SC [33-36]. Isolates of Aspergillus spp. for which the triazole MIC results exceeded the ECV are considered to be non-wildtype (NWT) and may harbor acquired mutations in the cyp51A gene $[6,7,27,35-38]$.

\section{Quality control}

Quality control (QC) was performed in accordance with CLSI guidelines using A. flavus ATCC 204304 and A. 
Table 1 Geographic distribution of Aspergillus spp. collected during 2011-2019 in Asia and Western Pacific Region medical centers participating in the SENTRY Antifungal Surveillance Program

\begin{tabular}{|c|c|c|c|c|c|c|c|}
\hline $\begin{array}{l}\text { Organism/ } \\
\text { organism group }\end{array}$ & Australia & China & Korea & New Zealand & Singapore & Thailand & Total \\
\hline All Aspergillus spp. & 164 & 34 & 26 & 13 & 2 & 79 & 318 \\
\hline A. fumigatus & 113 & 20 & 6 & 11 & 1 & 38 & 189 \\
\hline A. flavus SC & 4 & 9 & 9 & & & 21 & 43 \\
\hline A. niger SC & 24 & 4 & 6 & & & 12 & 46 \\
\hline A. terreus SC & 6 & 1 & 2 & & 1 & 4 & 14 \\
\hline A. nidulans SC & 11 & & & & & & 11 \\
\hline A. tamarii & 1 & & & 1 & & 1 & 3 \\
\hline A. versicolor & 1 & & 2 & & & & 3 \\
\hline A. tubingensis & 1 & & 1 & & & & 2 \\
\hline A. aculeatus & & & & & & 1 & 1 \\
\hline A. clavatus & & & & & & 1 & 1 \\
\hline A. foetidus & 1 & & & & & & 1 \\
\hline A. lentulus & 1 & & & 1 & & & 2 \\
\hline A. ochraceus $\mathrm{SC}$ & & & & & & 1 & 1 \\
\hline A. ustus SC & 1 & & & & & & 1 \\
\hline
\end{tabular}

${ }^{a} S C$ species complex fumigatus ATCC MYA-3626 [32]. All MIC values were within their respective $\mathrm{QC}$ ranges [39].

\section{Results}

\section{Activity of mold-active azoles against Aspergillus spp. from APAC, 2011-2019}

A total of 318 clinical isolates of Aspergillus spp. were tested in the surveillance years of 2011-2019 and are presented in Table 1. Isolates were obtained from six countries, including Australia (164 isolates), Thailand (79 isolates), China (34 isolates), Korea (26 isolates), New Zealand (13 isolates), and Singapore (2 isolates). During the study period, 14 different species or SC were identified, including: $A$. fumigatus (189 isolates), A. flavus SC (43 isolates), A. niger SC (46 isolates), A. terreus SC (14 isolates), A. nidulans SC (11 isolates), A. tamarii (3 isolates), A. versicolor (3 isolates), A. tubingensis (2 isolates), A. lentulus (2 isolates), and single isolates of $A$. aculeatus, A. clavatus, A. foetidus, A. ochraceus SC, and A. ustus SC (Table 1).

The in vitro activities of the four mold-active triazoles against Aspergillus spp. are shown in Table 2. Similar activities were observed when isavuconazole $\left(\mathrm{MIC}_{50} \mathrm{l}_{90}, 0.5 / 2 \mathrm{mg}^{-1}\right.$ ), itraconazole $\left(\mathrm{MIC}_{50} / 90, \quad 0.5 / 1 \mathrm{mg} \mathrm{l}^{-1}\right.$ ), and voriconazole $\left(\mathrm{MIC}_{50} \mathrm{l}_{90}, 0.5 / 1 \mathrm{mg} \mathrm{l}^{-1}\right.$ ) were tested against Aspergillus spp. isolates. Those activities were 1-2-fold dilutions higher than posaconazole ( $\mathrm{MIC}_{50} / 90,0.25 / 0.5 \mathrm{mg} \mathrm{l}^{-1}$ ). A. fumigatus displayed $\mathrm{MIC}_{90}$ values of $1 \mathrm{mg} \mathrm{l}^{-1}$ for isavuconazole and itraconazole and $0.5 \mathrm{mg} \mathrm{l}^{-1}$ for posaconazole and voriconazole (Table 2). Most of the A. fumigatus isolates tested were WT to isavuconazole (94.3\% [CLSI ECV]), itraconazole (97.9\% [CLSI ECV]), and voriconazole (98.9\% [CLSI ECV]). In addition, the voriconazole susceptibility rate against $A$. fumigatus was $95.8 \%$ when the CLSI breakpoint was applied. Posaconazole does not have a CLSI-published ECV criteria against $A$. fumigatus, but there has been discussion of whether the ECV should be 0.25 or $0.5 \mathrm{mg}^{-1}$ [40]. If the ECV for posaconazole were to be set at $0.5 \mathrm{mg}^{-1}, 98.9 \%$ of A. fumigatus isolates in this collection would be WT. The overall frequency of NWT strains of A. fumigatus was $1.1 \%$ for posaconazole and voriconazole, $2.1 \%$ for itraconazole, and $5.7 \%$ for isavuconazole. All NWT strains originated from either Australia or Thailand (data not shown).

The $\mathrm{MIC}_{90}$ values were $1 \mathrm{mg} \mathrm{l}^{-1}$ for itraconazole, isavuconazole, and voriconazole and $0.5 \mathrm{mg}^{-1}$ for posaconazole and A. flavus SC, with 100.0\%, 94.7\%, 100.0\%, and $97.7 \%$ of the isolates considered as WT, respectively (Table 2). The isavuconazole $\mathrm{MIC}_{90}$ value of $4 \mathrm{mg} \mathrm{l}^{-1}$ for $A$. niger SC (Table 2) was comparable to the $\mathrm{MIC}_{90}$ of itraconazole $\left(2 \mathrm{mg}^{-1}\right)$ and higher than the $\mathrm{MIC}_{90}$ of posaconazole $\left(1 \mathrm{mg} \mathrm{l}^{-1}\right)$ and voriconazole $\left(1 \mathrm{mg} \mathrm{l}^{-1}\right)$. The WT percent for A. niger SC was $100.0 \%$ for isavuconazole, posaconazole, and voriconazole and $97.8 \%$ for itraconazole (Table 2). All isolates of A. terreus SC were WT to all four triazoles. A. nidulans SC, A. tamarii, and A. versicolor were all susceptible to these agents, with $\mathrm{MIC}_{50 / 90}$ values of $0.03-0.5 \mathrm{mg} \mathrm{l}^{-1}$.

There were nine isolates of rare Aspergillus species represented by one or two isolates each. These rare Aspergillus species included: A. tubingensis (2 isolates), A. aculeatus (1 isolate), A. clavatus (1 isolate), A. foetidus (1 isolate), A. lentulus (2 isolates), A. ochraceus SC (1 isolate), 
Table 2 Antifungal activity of isavuconazole and comparator antifungal agents against Aspergillus spp. collected during 2011-2019 in APAC medical centers participating in the SENTRY Antifungal Surveillance Program

\begin{tabular}{|c|c|c|c|c|c|c|}
\hline \multirow[t]{2}{*}{ Species } & \multirow[t]{2}{*}{ Antifungal agent (no. tested) } & \multicolumn{3}{|c|}{$\mathrm{MIC}\left(\mu \mathrm{g} \mathrm{ml}^{-1}\right)$} & \multicolumn{2}{|l|}{$\mathrm{ECV}$} \\
\hline & & Range & $50 \%$ & $90 \%$ & $\% \mathrm{WT}$ & $\%$ NWT \\
\hline \multirow[t]{4}{*}{ Aspergillus spp. } & Isavuconazole (126) & $0.015-4$ & 0.5 & 2 & & \\
\hline & Itraconazole (319) & $0.12->8$ & 0.5 & 1 & & \\
\hline & Posaconazole (319) & $0.03->8$ & 0.25 & 0.5 & & \\
\hline & Voriconazole (319) & $0.03-4$ & 0.5 & 1 & & \\
\hline \multirow[t]{4}{*}{ A. fumigatus } & Isavuconazole (70) & $0.25-2$ & 0.5 & 1 & 94.3 & 5.7 \\
\hline & Itraconazole (189) & $0.25->8$ & 0.5 & 1 & 97.9 & 2.1 \\
\hline & Posaconazole (189) & $0.03->8$ & 0.25 & 0.5 & $98.9^{\mathrm{a}}$ & 1.1 \\
\hline & Voriconazole (189) & $0.06-4$ & 0.5 & 0.5 & 98.9 & 1.1 \\
\hline \multirow[t]{4}{*}{ A. flavus SC } & Isavuconazole (19) & $0.5-2$ & 0.5 & 1 & 94.7 & 5.3 \\
\hline & Itraconazole (43) & $0.25-1$ & 0.5 & 1 & 100.0 & 0.0 \\
\hline & Posaconazole (43) & $0.12-1$ & 0.25 & 0.5 & 97.7 & 2.3 \\
\hline & Voriconazole (43) & $0.12-2$ & 0.5 & 1 & 100.0 & 0.0 \\
\hline \multirow[t]{4}{*}{ A. niger $\mathrm{SC}$} & Isavuconazole (18) & $0.12-4$ & 2 & 4 & 100.0 & 0.0 \\
\hline & Itraconazole (46) & $0.12-8$ & 1 & 2 & 97.8 & 2.2 \\
\hline & Posaconazole (46) & $0.06-1$ & 0.5 & 1 & 100.0 & 0.0 \\
\hline & Voriconazole (46) & $0.06-2$ & 1 & 1 & 100.0 & 0.0 \\
\hline \multirow[t]{4}{*}{ A. terreus SC } & Isavuconazole (6) & $0.06-0.5$ & 0.12 & & 100.0 & 0.0 \\
\hline & Itraconazole (14) & $0.25-1$ & 0.5 & 1 & 100.0 & 0.0 \\
\hline & Posaconazole (14) & $0.12-0.5$ & 0.25 & 0.25 & 100.0 & 0.0 \\
\hline & Voriconazole (14) & $0.06-0.5$ & 0.25 & 0.5 & 100.0 & 0.0 \\
\hline \multirow[t]{4}{*}{ A. nidulans SC } & Isavuconazole (6) & $0.015-0.25$ & 0.03 & & & \\
\hline & Itraconazole (11) & $0.12-1$ & 0.5 & 0.5 & & \\
\hline & Posaconazole (11) & $0.06-0.5$ & 0.25 & 0.5 & & \\
\hline & Voriconazole (11) & $0.03-0.5$ & 0.12 & 0.25 & & \\
\hline \multirow[t]{4}{*}{ A. tamari } & Isavuconazole (2) & $0.12-0.25$ & 0.12 & & & \\
\hline & Itraconazole (3) & $0.25-0.5$ & 0.25 & & & \\
\hline & Posaconazole (3) & $0.06-0.25$ & 0.12 & & & \\
\hline & Voriconazole (3) & $0.12-0.5$ & 0.25 & & & \\
\hline \multirow[t]{4}{*}{ A. versicolor } & Isavuconazole (1) & 0.5 & & & & \\
\hline & Itraconazole (3) & $0.5-1$ & 0.5 & & & \\
\hline & Posaconazole (3) & 0.5 & 0.5 & & & \\
\hline & Voriconazole (3) & $0.25-0.5$ & 0.5 & & & \\
\hline
\end{tabular}

$S C$ species complex

${ }^{\mathrm{a} U s i n g}$ an ECV of $\leq 0.5 \mathrm{mg}^{-1}[40]$. and $A$. ustus SC (1 isolate) (Table 1). The azole MIC values were generally less than $2 \mathrm{mg}^{-1}$ for each agent and were comparable to the values seen with A. fumigatus (data not shown). Isavuconazole MIC values of $2 \mathrm{mg}^{-1}$ were seen with A. tubingensis and A. lentulus.

\section{Activity of mold-active azoles against non- Aspergillus molds from APAC, 2011-2019}

A total of 53 isolates of non-Aspergillus molds were tested in the surveillance years 2011-2019 and are presented in Table 3. Isolates were obtained from four countries, including Australia (33 isolates), Thailand (10 isolates),
Korea (5 isolates), and New Zealand (5 isolates). These organisms included 23 species or SC, but most organisms were represented by 4 or fewer strains. In this survey, the most frequent of these uncommon molds were the Scedosporium spp (S. apiospermum [1 isolate], S. apiospermum/S. boydii [9 isolates], and $S$. aurantiacum [7 isolates]) and Lomentospora prolificans (6 isolates), all of which were from either Australia or New Zealand (Table 3). The in vitro activity of isavuconazole, posaconazole, and voriconazole against these molds are shown in Table 4. Although the small number of isolates from each species makes it difficult to obtain conclusions regarding the activity of the triazoles, there are some clear patterns. First, none of the triazoles 
Table 3 Geographic distribution of non-Aspergillus molds collected during 2011-2019 APAC medical centers participating in the SENTRY Antifungal Surveillance Program

\begin{tabular}{|c|c|c|c|c|c|}
\hline $\begin{array}{l}\text { Organism/ } \\
\text { organism group }\end{array}$ & Australia & Korea & $\begin{array}{l}\text { New } \\
\text { Zealand }\end{array}$ & Thailand & Total \\
\hline Fusarium solani $S C$ & & & & 4 & 4 \\
\hline $\begin{array}{l}\text { Lichtheimia } \\
\text { corymbifera }\end{array}$ & 1 & & & & 1 \\
\hline L. ramosa & & 1 & 1 & & 2 \\
\hline Mucor circinelloides & & & 1 & & 1 \\
\hline Rhizoтисоr pusillus & & & & 1 & 1 \\
\hline Rhizopus microsporus & & 2 & & & 2 \\
\hline R. oryzae SC & 3 & & & 1 & 4 \\
\hline Cunninghamella sp. & 1 & & & & 1 \\
\hline Syncephalastrum sp. & & & & 1 & 1 \\
\hline Scedosporium spp $^{\mathrm{a}}$ & 15 & & 2 & & 17 \\
\hline $\begin{array}{l}\text { Exophiala } \\
\text { dermatitidis }\end{array}$ & 1 & & & & 1 \\
\hline $\begin{array}{l}\text { Lomentospora } \\
\text { prolificans }\end{array}$ & 6 & & & & 6 \\
\hline $\begin{array}{l}\text { Purpureocillium } \\
\text { lilacinum }\end{array}$ & 1 & & & 1 & 2 \\
\hline $\begin{array}{l}\text { Pleurostoma } \\
\text { richardsiae }\end{array}$ & & & & 1 & 1 \\
\hline $\begin{array}{l}\text { Rasamsonia } \\
\text { argillacea }\end{array}$ & 1 & & & & 1 \\
\hline $\begin{array}{l}\text { Trichoderma } \\
\text { longibrachiatum }\end{array}$ & 1 & & & & 1 \\
\hline Curvularia spp. & 2 & & & & 2 \\
\hline Paecilomyces spp. & & 2 & & & 2 \\
\hline Phaeoacremonium sp. & 1 & & & & 1 \\
\hline Phialemoniopsis sp. & & & & 1 & 1 \\
\hline Verruconis gallopava & & & 1 & & 1 \\
\hline Total & 33 & 5 & 5 & 10 & 53 \\
\hline
\end{tabular}

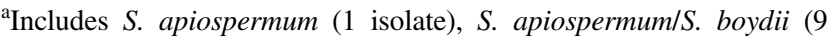
isolates), and $S$. auriantiacum (7 isolates)

showed activity against Fusarium solani SC or L. prolificans. The individual species of Scedosporium were more susceptible to voriconazole (MIC range $0.12-8 \mathrm{mg}^{-1}$; MICs $\leq 1 \mathrm{mg}^{-1}$ for $15 / 17$ isolates) than either isavuconazole (MIC range $1->8 \mathrm{mg} \mathrm{l}^{-1}$; MICs $\geq 4 \mathrm{mg}^{-1}$ for $7 / 8$ isolates tested) or posaconazole (MIC range $0.5->8 \mathrm{mg}^{-1}$; MICs $\geq 2 \mathrm{mg} \mathrm{l}^{-1}$ for $13 / 17$ isolates tested). Thirteen isolates from the Mucorales group were tested in this survey, including Lichtheimia corymbifera, L. ramosa, Mucor circinelloides, Rhizomucor pusilus, Rhizopus microsporus group, $R$. oryzae SC, Cunninghamella sp., and Syncephalastrum $\mathrm{sp}$. The Mucorales group MIC values for posaconazole ranged from 0.5 to $4 \mathrm{mg} \mathrm{l}^{-1}$, with MIC values $\leq 1 \mathrm{mg}$ $\mathrm{1}^{-1}$ for $9 / 13$ isolates. Isavuconazole MIC values of $2 \mathrm{mg} \mathrm{l}^{-1}$ were seen for $L$. corymbifera, $R$. microsporus group, and Syncephalastrum sp., but were $>8 \mathrm{mg}^{-1}$ for isolates of $R$. oryzae SC. Voriconazole was inactive against the Mucorales group. Among the remaining species of rare molds, elevated MIC values $\left(>8 \mathrm{mg} \mathrm{l}^{-1}\right.$ ) for both isavuconazole and voriconazole were seen in the Rasamsonia argillacea and Paecilomyces sp. isolates. One isolate of Purpureocillium lilacinum was resistant (MIC $\geq 8 \mathrm{mg}^{-1}$ ) to both posaconazole and voriconazole. The triazoles were all active (MIC $\leq 1 \mathrm{mg}^{-1}$ ) against isolates of Curvularia sp., Phialemoniopsis sp., Pleurostoma richardsiae, and Verruconis gallopava.

\section{Discussion}

The majority of IMI are a result of the so-called Big Five mold killers of humans [3]: Aspergillus, Fusarium, Lomentospora, Scedosporium, and the Mucorales. Although the epidemiology of IMI is not well described in the APAC region, surveys indicate a rising incidence of infections due to the Big Five $[2,14]$. In the present survey, we noted the prominence of Aspergillus, Lomentospora, Scedosporium, and the Mucorales among isolates causing IMI from the APAC region in the SENTRY Antifungal Surveillance Program (Tables 1 and 3). Significantly, an additional 12 different species of rare molds were characterized in this survey, facilitated by MALDI-TOF MS and DNA sequence analysis for accurate organism identification (Table 3).

As expected, A. fumigatus was the leading pathogen overall (Table 1). In contrast to the high level of resistance to the triazoles reported from Europe [5, 6, 13, 36], greater than $94 \%$ of the APAC isolates were WT to the mold-active triazoles, isavuconazole, itraconazole, posaconazole, and voriconazole (Table 2). We also identified an additional 13 different species of Aspergillus, which accounted for 40.6 of the total Aspergillus isolates in the collection (Table 1). Although the number of each of these rare species is small, it is important to document their occurrence and antifungal susceptibility profile as the data in the literature are quite limited. As with A. fumigatus, the great majority of these non-fumigatus species appear to represent WT strains with little acquired resistance to the triazoles (Table 2).

Whereas the Aspergillus species in Table 2 appear to maintain susceptibility to the triazoles, this is not the case with most of the non-Aspergillus molds (Table 4). Diagnosis of infection with these miscellaneous fungal pathogens seems to be increasing both worldwide and in the APAC region $[2,3,9,10,12,14,41]$. This finding may be due to the increased identification of clinical isolates of molds using MALDI-TOF MS or DNA sequence analysis, but it also could be attributed to both the immunodeficient state of patients in the region, often complicated by cavitary tuberculosis $[1,21,24,26]$, and the innate resistance of these organisms to antifungal agents $[9,14,41]$. 
Table 4 Antifungal activity of isavuconazole and comparator antifungal agents for non-Aspergillus mold isolates collected during 2011-2019 in Asia-Western Pacific medical centers participating in the SENTRY Antifungal Surveillance Program

\begin{tabular}{|c|c|c|c|}
\hline \multirow[t]{2}{*}{ Organism } & \multicolumn{3}{|c|}{ MIC results in $\mathrm{mg}^{-1 \text { a }}$} \\
\hline & Isavuconazole & Posaconazole & Voriconazole \\
\hline Fusarium solani species complex & $>8$ & $>8$ & $>8$ \\
\hline Fusarium solani species complex & $>8$ & $>8$ & 4 \\
\hline Fusarium solani species complex & $>8$ & $>8$ & 8 \\
\hline Fusarium solani species complex & NT & $>8$ & $>8$ \\
\hline Lichtheimia corymbifera & 2 & 0.5 & $>8$ \\
\hline Lichtheimia ramosa & NT & 1 & $>8$ \\
\hline Lichtheimia ramosa & NT & 0.5 & $>8$ \\
\hline Mucor circinelloides & NT & 2 & $>8$ \\
\hline Rhizomисоr pusillus & NT & 0.5 & $>8$ \\
\hline Rhizopus microsporus group & 2 & 2 & $>8$ \\
\hline Rhizopus microsporus group & 2 & 0.5 & $>8$ \\
\hline Rhizopus oryzae SC & $>8$ & 1 & $>8$ \\
\hline Rhizopus oryzae SC & $>8$ & 2 & $>8$ \\
\hline Rhizopus oryzae SC & $>8$ & 4 & $>8$ \\
\hline Rhizopus oryzae SC & NT & 0.5 & $>8$ \\
\hline Cunninghamella sp. & 8 & 1 & $>8$ \\
\hline Syncephalastrum sp. & 2 & 0.5 & $>8$ \\
\hline Scedosporium apiospermum & NT & 1 & 1 \\
\hline Scedosporium apiospermum/S. boydii & NT & 1 & 0.12 \\
\hline Scedosporium apiospermum/S. boydii & NT & 0.5 & 0.5 \\
\hline Scedosporium apiospermum/S. boydii & 4 & 1 & 0.5 \\
\hline Scedosporium apiospermum/S. boydii & 4 & 2 & 0.5 \\
\hline Scedosporium apiospermum/S. boydii & 4 & 4 & 0.5 \\
\hline Scedosporium apiospermum/S. boydii & NT & 2 & 1 \\
\hline Scedosporium apiospermum/S. boydii & $>8$ & 2 & 1 \\
\hline Scedosporium apiospermum/S. boydii & 8 & 2 & 4 \\
\hline Scedosporium apiospermum/S. boydii & 1 & $>8$ & 8 \\
\hline Scedosporium aurantiacum & NT & 2 & 0.5 \\
\hline Scedosporium aurantiacum & NT & 2 & 0.5 \\
\hline Scedosporium aurantiacum & 8 & 2 & 0.5 \\
\hline Scedosporium aurantiacum & 8 & 2 & 0.5 \\
\hline Scedosporium aurantiacum & NT & 2 & 1 \\
\hline Scedosporium aurantiacum & NT & 2 & 1 \\
\hline Scedosporium aurantiacum & NT & 2 & 1 \\
\hline Exophiala dermatitidis & 1 & 0.25 & 0.25 \\
\hline Lomentospora prolificans & NT & $>8$ & 8 \\
\hline Lomentospora prolificans & NT & $>8$ & $>8$ \\
\hline Lomentospora prolificans & NT & $>8$ & $>8$ \\
\hline Lomentospora prolificans & NT & $>8$ & $>8$ \\
\hline Lomentospora prolificans & $>8$ & $>8$ & $>8$ \\
\hline Lomentospora prolificans & $>8$ & $>8$ & $>8$ \\
\hline Purpureocillium lilacinum & 0.5 & 0.5 & 0.25 \\
\hline Purpureocillium lilacinum & NT & $>8$ & 8 \\
\hline Pleurostoma richardsiae & 0.5 & 0.5 & 0.5 \\
\hline Rasamsonia argillacea & $>8$ & 2 & $>8$ \\
\hline
\end{tabular}


Table 4 (continued)

\begin{tabular}{llll}
\hline Organism & \multicolumn{2}{l}{ MIC results in mg 1 } \\
\cline { 2 - 4 } & Isavuconazole & Posaconazole & Voriconazole \\
\hline Trichoderma longibrachiatum & $\mathrm{NT}$ & 2 & 0.5 \\
Curvularia sp. & 0.5 & 0.25 & 0.5 \\
Curvularia sp. & 1 & 0.5 & 0.5 \\
Paecilomyces sp. & $>8$ & 0.25 & $>8$ \\
Paecilomyces sp. & $>8$ & 0.25 & $>8$ \\
Phaeoacremonium sp. & 2 & 0.5 & 0.5 \\
Phialemoniopsis sp. & 0.5 & 0.25 & 0.25 \\
Verruconis gallopava & 1 & 0.06 & 0.25 \\
\hline
\end{tabular}

${ }^{a} N T$ not tested

Among the rare molds identified in the present survey, the most common were Mucorales, Scedosporium, and Lomentospora (Table 3). As observed previously [2, 12, 16], Scedosporium and Lomentospora were almost exclusively found in Australia (Table 3). Isolates of $L$. prolificans were pan-azole-resistant whereas Scedosporium spp. isolates were most susceptible $\left(\mathrm{MIC}_{50 / 90}, 0.5 / 1 \mathrm{mg} \mathrm{l}^{-1}\right)$ to voriconazole (Table 4). The Mucorales were represented by eight different species, all of which were resistant (MIC $\geq 8 \mathrm{mg} \mathrm{l}^{-1}$ ) to voriconazole (Table 4). Posaconazole was the most potent triazole against the Mucorales, with MICs ranging from 0.5 to $4 \mathrm{mg}^{-1}$ (Table 4). Isavuconazole showed activity (MIC $2 \mathrm{mg}^{-1}$ ) against Lichtheimia corymbifera, Rhizopus microsporus group, and Syncephalastrum sp., but was not active (MIC $\geq 8 \mathrm{mg} \mathrm{l}^{-1}$ ) against Rhizopus oryzae (Table 4). These findings highlight the need for both accurate identification and antifungal susceptibility testing to optimize the treatment of infections due to the Mucorales [3].

Among the remaining fungi, Fusarium solani SC was resistant (MIC $\geq 4 \mathrm{mg}^{-1}$ ) to all the tested azoles and Rasamsonia argillacea and Paecilomyces sp. were resistant to isavuconazole and voriconazole (Table 4).

Isolates of Curvularia, Phaeoacremonium, Phialemoniopsis, and Verruconis gallopava were generally susceptible ( $\mathrm{MIC} \leq 1 \mathrm{mg} \mathrm{l}^{-1}$ ) to isavuconazole, posaconazole, and voriconazole (Table 4).

Although many patients with IMI have traditional predisposing factors, such as immunosuppression due to hematological malignancy, blood and marrow transplantation, and solid organ transplantation, these infections are being reported increasingly in non-immunosuppressed individuals [1, 3, 12, 42-44].

Most recently, IMI has been shown to complicate the course of respiratory viral infections, including SARS-CoV2 and influenza [42-44]. Emerging at-risk populations include those with chronic lung disease (patients receiving steroids and TNF antagonists) and traumatic injuries [3].
Significantly, in the APAC region, both invasive pulmonary aspergillosis and chronic forms of aspergillosis are seen in the setting of cavitary tuberculosis [1, 21, 24, 26]. Traumatic implantation of the non-Aspergillus molds, especially the Mucorales and Scedosporium spp., is another route of infection in immunocompetent individuals [3, 12].

Given the lack of azole resistance among isolates of Aspergillus from the APAC region, the role of mold-active triazoles as first-line agents in the treatment and prophylaxis in high-risk individuals is confirmed [36, 45, 46]. The wide variation in species and antifungal resistance profiles seen among the non-Aspergillus molds pose considerable difficulties in patient management [9]. Management of these infections is complicated and prolonged [3]. Extended antifungal therapy, often with two or more agents [9, 47, 48], may be required. Adjunctive surgery is often indicated as a means of source control and to decrease the organism burden [9, 12, 14].

In summary, we have documented the prominence of Aspergillus spp. as a cause of IMI in the APAC region, and these isolates remain susceptible/WT to the mold-active triazoles. As the most recently introduced azole, isavuconazole has been shown to be very active against Aspergillus spp., including the lesser-known non-fumigatus species (Table 2). We have documented the in vitro activity of isavuconazole against Aspergillus spp. since 2010 with no change in the MIC distribution over 9 years [10, 11, 15, 28, 31].

In contrast to Aspergillus spp., the less common opportunistic molds show a great deal of variety in species and associated resistance profiles [9, 12, 14, 41]. Most prominently, isolates of Fusarium solani SC, L. prolificans, and the Mucorales express resistance to one or more of the mold-active triazoles, complicating the use of these agents empirically [9]. These findings underscore the importance of building mycological expertise in the APAC region [8]. At present, there is almost no access to advanced diagnostic tests (galactomannan, $\beta$-D-glucan, or PCR) in many APAC 
countries and few laboratories perform DNA sequencing (16.9\%) or use MALDI-TOF MS (12.3\%) for isolate identification [8]. Antifungal testing for molds is performed in only $27 \%$ of laboratories in the APAC region. Increased use of biomarkers (e.g., galactomannan or $\beta$-D-glucan) may aid in the diagnosis of invasive pulmonary aspergillosis, but application of proteomic and molecular methods for identification and performance of antifungal susceptibility testing will be necessary to address infections with nonfumigatus species of Aspergillus as well as the non-Aspergillus molds [3, 9]. Accurate identification and the broader application of antifungal susceptibility testing are crucial requirements to find the optimal treatment options for patients with IMI as well as for detection of resistance [49].

Acknowledgements This study was performed by JMI Laboratories and supported by Pfizer. MAP, CGC, PR, SM, and MC are employees of JMI Laboratories, which was a paid consultant to Pfizer in connection with the development of this manuscript. JMI Laboratories contracted to perform services in 2020 for Affinity Biosensors, Allergan, Amicrobe, Inc., Amplyx Pharma, Artugen Therapeutics USA, Inc., Astellas, Basilea, Beth Israel Deaconess Medical Center, BIDMC, bioMerieux, Inc., BioVersys Ag, Bugworks, Cidara, Cipla, Contrafect, Cormedix, Crestone, Inc., Curza, CXC7, Entasis, Fedora Pharmaceutical, Fimbrion Therapeutics, Fox Chase, GlaxoSmithKline, Guardian Therapeutics, Hardy Diagnostics, IHMA, Janssen Research \& Development, Johnson \& Johnson, Kaleido Biosciences, KBP Biosciences, Luminex, Matrivax, Mayo Clinic, Medpace, Meiji Seika Pharma Co., Ltd., Melinta, Menarini, Merck, Meridian Bioscience Inc., Micromyx, MicuRx, N8 Medical, Nabriva, National Institutes of Health, National University of Singapore, North Bristol NHS Trust, Novome Biotechnologies, Paratek, Pfizer, Prokaryotics Inc., QPEX Biopharma, Rhode Island Hospital, RIHML, Roche, Roivant, Salvat, Scynexis, SeLux Diagnostics, Shionogi, Specific Diagnostics, Spero, SuperTrans Medical LT, T2 Biosystems, The University of Queensland, Thermo Fisher Scientific, Tufts Medical Center, Université de Sherbrooke, University of Iowa, University of Iowa Hospitals and Clinics, University of Wisconsin, UNT System College of Pharmacy, URMC, UT Southwestern, VenatoRx, Viosera Therapeutics, and Wayne State University. There are no speakers' bureaus or stock options to declare.

\section{Compliance with ethical standards}

Conflict of interest The authors declare no competing interests.

Publisher's note Springer Nature remains neutral with regard to jurisdictional claims in published maps and institutional affiliations.

Open Access This article is licensed under a Creative Commons Attribution 4.0 International License, which permits use, sharing, adaptation, distribution and reproduction in any medium or format, as long as you give appropriate credit to the original author(s) and the source, provide a link to the Creative Commons license, and indicate if changes were made. The images or other third party material in this article are included in the article's Creative Commons license, unless indicated otherwise in a credit line to the material. If material is not included in the article's Creative Commons license and your intended use is not permitted by statutory regulation or exceeds the permitted use, you will need to obtain permission directly from the copyright holder. To view a copy of this license, visit http://creativecommons. org/licenses/by/4.0/.

\section{References}

1. Bongomin F, Gago S, Oladele RO, Denning DW. Global and multi-national prevalence of fungal diseases-estimate precision. $\mathrm{J}$ Fungi (Basel). 2017;3:e57.

2. Slavin MA, Chakrabarti A. Opportunistic fungal infections in the Asia-Pacific region. Med Mycol. 2012;50:18-25.

3. Thornton CR. Detection of the 'big five' mold killers of humans: Aspergillus, Fusarium, Lomentospora, Scedosporium and Mucormycetes. Adv Appl Microbiol. 2020;110:1-61.

4. Heo ST, Tatara AM, Jimenez-Ortigosa C, Jiang Y, Lewis RE, Tarrand $\mathrm{J}$, et al. Changes in in vitro susceptibility patterns of aspergillus to triazoles and correlation with aspergillosis outcome in a tertiary care cancer center, 1999-2015. Clin Infect Dis. 2017;65:216-25.

5. Lestrade PPA, Buil JB, van der Beek MT, Kuijper EJ, van Dijk K, Kampinga GA, et al. Paradoxal trends in azole-resistant Aspergillus fumigatus in a national multicenter surveillance program, the Netherlands, 2013-2018. Emerg Infect Dis. 2020;26.

6. Rivero-Menendez O, Alastruey-Izquierdo A, Mellado E, CuencaEstrella M. Triazole resistance in Aspergillus spp.: a worldwide problem? J Fungi (Basel). 2016;2:E21.

7. van der Linden JW, Arendrup MC, Warris A, Lagrou K, Pelloux $\mathrm{H}$, Hauser PM, et al. Prospective multicenter international surveillance of azole resistance in Aspergillus fumigatus. Emerg Infect Dis. 2015;21:1041-4.

8. Chindamporn A, Chakrabarti A, Li R, Sun PL, Tan BH, Chua M, et al. Survey of laboratory practices for diagnosis of fungal infection in seven Asian countries: an Asia Fungal Working Group (AFWG) initiative. Med Mycol. 2018;56:416-25.

9. Araujo R, Oliveira M, Amorim A, Sampaio-Maia B. Unpredictable susceptibility of emerging clinical moulds to tri-azoles: review of the literature and upcoming challenges for mould identification. Eur J Clin Microbiol Infect Dis. 2015;34:1289-301.

10. Messer SA, Carvalhaes CG, Castanheira M, Pfaller MA. In vitro activity of isavuconazole versus opportunistic filamentous fungal pathogens from the SENTRY Antifungal Surveillance Program, 2017-2018. Diagn Microbiol Infect Dis. 2020; 97:115007.

11. Pfaller MA, Rhomberg PR, Wiederhold NP, Gibas C, Sanders C, Fan $\mathrm{H}$, et al. In vitro activity of isavuconazole versus opportunistic fungal pathogens from two mycology reference laboratories. Antimicrob Agents Chemother. 2018;62:e01230.

12. Slavin M, van Hal S, Sorrell TC, Lee A, Marriott DJ, Daveson K, et al. Invasive infections due to filamentous fungi other than Aspergillus: epidemiology and determinants of mortality. Clin Microbiol Infect. 2015;21:490.e1-10.

13. Verweij PE, Chowdhary A, Melchers WJ, Meis JF. Azole resistance in Aspergillus fumigatus: Can we retain the clinical use of mold-active antifungal azoles? Clin Infect Dis. 2016;62:362-8.

14. Hsiue HC, Ruan SY, Kuo YL, Huang YT, Hsueh PR. Invasive infections caused by non-Aspergillus moulds identified by sequencing analysis at a tertiary care hospital in Taiwan, 20002008. Clin Microbiol Infect. 2010;16:1204-6.

15. Pfaller MA, Rhomberg PR, Messer SA, Jones RN, Castanheira M. Isavuconazole, micafungin, and 8 comparator antifungal agents' susceptibility profiles for common and uncommon opportunistic fungi collected in 2013: temporal analysis of antifungal drug resistance using CLSI species-specific clinical breakpoints and proposed epidemiological cutoff values. Diagn Microbiol Infect Dis. 2015;82:303-13.

16. Heath $\mathrm{CH}$, Slavin MA, Sorrell TC, Handke R, Harun A, Phillips $M$, et al. Population-based surveillance for scedosporiosis in Australia: epidemiology, disease manifestations and emergence of Scedosporium aurantiacum infection. Clin Microbiol Infect. 2009;15:689-93. 
17. Slavin MA, Australian Mycology Interest Group. The epidemiology of candidaemia and mould infections in Australia. $\mathrm{J}$ Antimicrob Chemother. 2002;49:3-6.

18. Chakrabarti A, Shivaprakash MR, Singh R, Tarai B, George VK, Fomda BA, et al. Fungal endophthalmitis: fourteen years' experience from a center in India. Retina 2008;28:1400-7.

19. Chakrabarti A, Chatterjee SS, Das A, Panda N, Shivaprakash MR, Kaur A, et al. Invasive zygomycosis in India: experience in a tertiary care hospital. Postgrad Med J. 2009;85:573-81.

20. Yamazaki T, Kume H, Murase S, Yamashita E, Arisawa M. Epidemiology of visceral mycoses: analysis of data in annual of the pathological autopsy cases in Japan. J Clin Microbiol. 1999;37:1732-8.

21. Huh K, Ha YE, Denning DW, Peck KR. Serious fungal infections in Korea. Eur J Clin Microbiol Infect Dis. 2017;36:957-63.

22. Kim HJ, Park YJ, Kim WU, Park SH, Cho CS. Invasive fungal infections in patients with systemic lupus erythematosus: experience from affiliated hospitals of Catholic University of Korea. Lupus 2009;18:661-6.

23. Tio TH, Djojopranoto M, Tyoei EN. Subcutaneous phycomycosis in children in East-Java. Paediatr Indones. 1965;5:519-26.

24. Chayakulkeeree M, Denning DW. Serious fungal infections in Thailand. Eur J Clin Microbiol Infect Dis. 2017;36:931-5.

25. Kiertiburanakul S, Thibbadee C, Santanirand P. Invasive aspergillosis in a tertiary-care hospital in Thailand. J Med Assoc Thai. 2007;90:895-902.

26. Huang YS, Denning DW, Shih SM, Hsiung CA, Wu UI, Sun HY, et al. Fungal diseases in Taiwan-national insurance data and estimation. J Fungi (Basel). 2019;5:78.

27. Pfaller M, Boyken L, Hollis R, Kroeger J, Messer S, Tendolkar S, et al. Use of epidemiological cutoff values to examine 9-year trends in susceptibility of Aspergillus species to the triazoles. J Clin Microbiol. 2011;49:586-90.

28. Pfaller MA, Messer SA, Rhomberg PR, Jones RN, Castanheira M. In vitro activities of isavuconazole and comparator antifungal agents tested against a global collection of opportunistic yeasts and molds. J Clin Microbiol. 2013;51:2608-16.

29. Pfaller MA, Diekema DJ, Turnidge JD, Castanheira M, Jones RN. Twenty years of the SENTRY Antifungal Surveillance Program: results for Candida species From 1997-2016. Open Forum Infect Dis 2019;6(Suppl 1):S79-94.

30. Pfaller MA, Woosley LN, Messer SA, Jones RN, Castanheira M. Significance of molecular identification and antifungal susceptibility of clinically significant yeasts and moulds in a global antifungal surveillance program. Mycopathologia 2012;174: 259-71.

31. Castanheira M, Messer SA, Jones RN, Farrell DJ, Pfaller MA. Activity of echinocandins and triazoles against a contemporary (2012) worldwide collection of yeast and moulds collected from invasive infections. Int J Antimicrob Agents 2014;44:320-6.

32. CLSI. M38Ed3. Reference method for broth dilution antifungal susceptibilty testing of filamentous fungi, third edition. Wayne, PA: Clinical and Laboratory Standards Institute; 2018.

33. Espinel-Ingroff A, Diekema DJ, Fothergill A, Johnson E, Pelaez T, Pfaller MA, et al. Wild-type MIC distributions and epidemiological cutoff values for the triazoles and six Aspergillus spp. for the CLSI broth microdilution method (M38-A2 document). J Clin Microbiol. 2010;48:3251-7.
34. CLSI. M59Ed2. Epidemiological cutoff values for antifungal susceptibility testing, second edition. Wayne, PA: Clinical and Laboratory Standards Institute; 2018.

35. Espinel-Ingroff A, Chowdhary A, Gonzalez GM, Lass-Florl C, Martin-Mazuelos E, Meis J, et al. Multicenter study of isavuconazole MIC distributions and epidemiological cutoff values for Aspergillus spp. for the CLSI M38-A2 broth microdilution method. Antimicrob Agents Chemother. 2013;57:3823-8.

36. Buil JB, Hagen F, Chowdhary A, Verweij PE, Meis JF. Itraconazole, voriconazole, and posaconazole CLSI MIC distributions for wild-type and azole-resistant Aspergillus fumigatus isolates. J Fungi (Basel). 2018;4:103.

37. van Ingen J, van der Lee HA, Rijs TA, Zoll J, Leenstra T, Melchers WJ, et al. Azole, polyene and echinocandin MIC distributions for wild-type, $\mathrm{TR}_{34} / \mathrm{L} 98 \mathrm{H}$ and $\mathrm{TR}_{46} / \mathrm{Y} 121 \mathrm{~F} / \mathrm{T} 289 \mathrm{~A}$ Aspergillus fumigatus isolates in the Netherlands. J Antimicrob Chemother 2015;70:178-81.

38. Wiederhold NP, Gil VG, Gutierrez F, Lindner JR, Albataineh MT, McCarthy DI, et al. First detection of $\mathrm{TR}_{34} \mathrm{~L} 98 \mathrm{H}$ and $\mathrm{TR}_{46} \mathrm{Y} 121 \mathrm{~F}$ T289A Cyp51 mutations in Aspergillus fumigatus isolates in the United States. J Clin Microbiol 2016;54:168-71.

39. CLSI. M61Ed1. Performance standards for antifungal susceptibility testing of filamentous fungi, first edition. Wayne, PA: Clinical and Laboratory Standards Institute; 2018.

40. Espinel-Ingroff A, Turnidge J, Alastruey-Izquierdo A, Dannaoui E, Garcia-Effron G, Guinea J, et al. Posaconazole MIC distributions for Aspergillus fumigatus species complex by four methods: Impact of cyp51A mutations on estimation of epidemiological cutoff values. Antimicrob Agents Chemother. 2018;62: e01916.

41. Miceli MH, Lee SA. Emerging moulds: epidemiological trends and antifungal resistance. Mycoses. 2011;54:e666-78.

42. Magira E, Chemaly RF, Jiang Y, Kontoyiannis DP. Invasive pulmonary aspergillosis (IPA) complicating respiratory viral infections in patients with hematological malignancies. Open Forum Infect Dis. 2018;5(Suppl 1):s140.

43. Thompson Iii GR, Cornely OA, Pappas PG, Patterson TF, Hoenigl $\mathrm{M}$, Jenks JD, et al. Invasive aspergillosis as an under-recognized superinfection in COVID-19. Open Forum Infect Dis. 2020;7: ofaa242.

44. Toda M, Beer K, O'Halloran A, Reingold A, Alden N, YouseyHindes $\mathrm{K}$, et al. Evidence of aspergillosis among patients with influenza-associated hospitalizations - United States, 2005-2017. Open Forum Infect Dis 2018;5(Suppl 1):S139-40.

45. Rauseo AM, Coler-Reilly A, Larson L, Spec A. Hope on the horizon: novel fungal treatments in development. Open Forum Infect Dis. 2020;7:ofaa016.

46. Van Daele R, Spriet I, Wauters J, Maertens J, Mercier T, Van Hecke S, et al. Antifungal drugs: what brings the future? Med Mycol. 2019;57(Supplement_3):S328-43.

47. Fohrer C, Fornecker L, Nivoix Y, Cornila C, Marinescu C, Herbrecht R. Antifungal combination treatment: a future perspective. Int J Antimicrob Agents. 2006;27:25-30.

48. Mukherjee PK, Sheehan DJ, Hitchcock CA, Ghannoum MA. Combination treatment of invasive fungal infections. Clin Microbiol Rev. 2005;18:163-94.

49. Kainz K, Bauer MA, Madeo F, Carmona-Gutierrez D. Fungal infections in humans: the silent crisis. Micro Cell. 2020;7:143-5. 